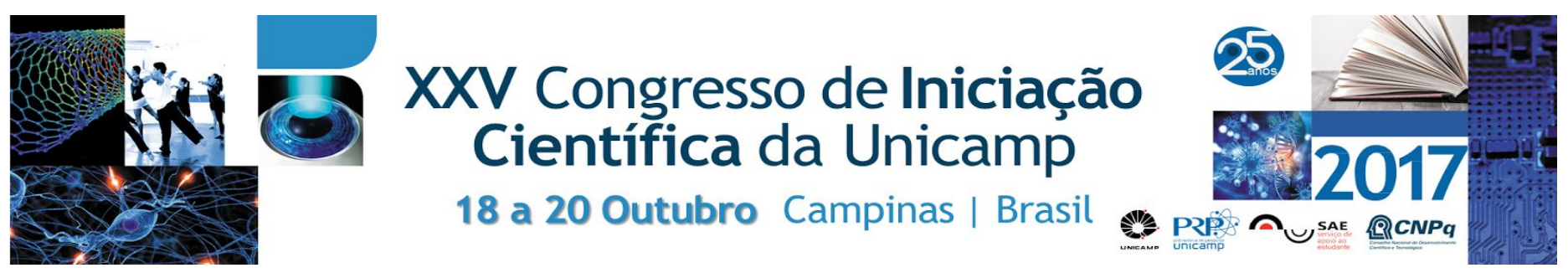

\title{
Automação de um sistema de fabricação de filmes ultrafinos automontados via Spray
}

\section{Marcos L. F. Gomes*, Varlei Rodrigues, Antonio Riul Jr.}

\section{Resumo}

Este trabalho científico teve por objetivo a automação de um sistema de fabricação de filmes ultrafinos automontados por adsorção física (LbL, do inglês layer-by-layer). É um projeto de instrumentação, sendo necessária a compreensão dos problemas que permeiam a nanoestruturação LbL via spray, para posteriormente desenvolver o aparato experimental de forma a automatizar a fabricação de filmes LbL. Utilizamos a técnica de impressão 3D em conjunto com o microcontrolador Arduíno uno para implementação do setup experimental.

\section{Palavras-chave:}

Layer-by-Layer, Automação, Impressão 3D

\section{Introdução}

Filmes finos possibilitam novas perspectivas em avanços tecnológicos como dispositivos eletrônicos, catálise, biomedicina e sensoriamento. A fabricação destes filmes, entretanto, não é trivial e está sendo amplamente estudada [1]. Existem 3 técnicas principais de fabricação de filmes ultrafinos automontados por adsorção física (LbL, do inglês layer-by-layer) que são dipping, spray e microfluídica $[1,2]$. Basicamente, a técnica LbL consiste na deposição camada a camada dos polieletrólitos com cargas opostas, com a nanoestruturação governada por interações intermoleculares (forças Coulombianas, van der Waals e ligações hidrogênio) [1]. No desenvolvimento deste projeto foi usada a técnica spray, baseada na adsorção dos polieletrólitos desejados sob a superfície de interesse.

Com a finalidade de automatizar o processo, foi utilizado um microcontrolador Arduíno Uno (open source) para o controle das etapas de fabricação do filme LbL. Já o aparato mecânico necessário para esta produção foi desenvolvido com base em técnicas usadas na construção de impressoras 3D.

\section{Resultados e Discussão}

A metodologia empregada, em geral, no crescimento de filmes finos é:

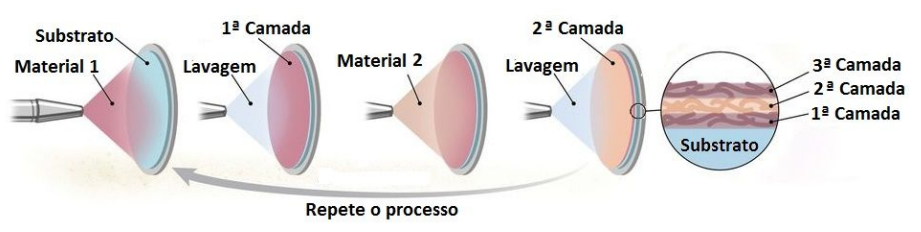

Figura 1. Formação de filmes finos pela técnica $\mathrm{LbL}$ por deposição spray. Adaptado de [1].

A automação do sistema é realizada pelo microcontrolador arduíno Uno e o perfil do aparato escolhido é uma adaptação de um sistema de movimentação de impressoras $3 \mathrm{D}$, permitindo controlar a posição de uma mesa no plano XY.
O interesse neste tipo de movimentação é posicionar o substrato onde será depositado o filme LbL, em frente a cada noozle e na distância necessária para que haja nanoestruturação otimizada dos polieletrólitos. Um esquema está ilustrado na Figura 2.
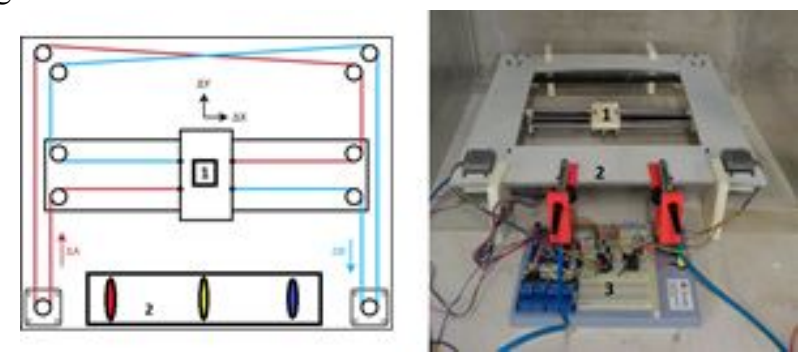

Figura 2. À esquerda uma ilustração e à direita uma foto do aparato mecânico. 1) Local de afixação da amostra. 2) Sprays ejetores de solução. 3) Eletrônica controladora do processo.

\section{Conclusões}

O aparato experimental proposto foi montado e está operacional. A próxima etapa é otimizar as distâncias dos noozles em função da pressão aplicada no sistema spray para fabricação e caracterização elétrica de um filme LbL. A continuação deste trabalho resultou em um projeto de mestrado no grupo de Física de Nanosistemas e Materiais Nanoestruturados mp IFGW (UNICAMP).

\section{Agradecimentos}

Agradecimentos à fonte de fomento PIBIC/CNPQ.

[1] Joseph J. Richardson, Mattias Björnmalm, Frank Caruso, Technology-driven layer-by-layer assembly of nanofilms, Science, 348, 411, 2015 .

[2] Grinia M. Nogueira, Debasish Banerjee, Robert E. Cohen and Michael F. Rubner, Spray-Layer-by-Layer Assembly Can More Rapidly Produce Optical-Quality Multistack Heterostructures, American Chemical Society 27, $7860,2011$. 